\title{
Explanation of the Donor Decision-making Process in the Czech Republic through a Combination of Influences of Individual Motives
}

\author{
Marie Hladká - Vladimír Hyánek
}

\begin{abstract}
:
Motivation represents a foundation corestone on which analyses in a number of the humanities and social sciences are built. For a long time, economists have seen motivation as connected with the act of giving, trying to interpret it in the context of the neoclassical economics assumptions. On the basis of representative theoretical models, Ziemek (2003) distinguishes three basic categories of motives underlying the act of giving: altruism, egoism and investment. The paper follows on from the research (Hladká, Hyánek, 2015) that generated interesting outcomes and presented a comprehensive picture of the motives influencing donor behaviour in the Czech Republic. The authors have enriched it with a new dimension in the form of an analysis and an appropriate research method. The authors submit a theoretically reasoned set of motives influencing donor behaviour to an explorative factor analysis with the aim to determine a group of the variables that statistically "belong together", i.e. are underpinned by a common factor. The result of the analysis is reduction of the original 37 identified motives to eight new aggregate factors which are newly named and can be used for further empirical testing.
\end{abstract}

Key words: Altruism; Charitable giving; Factor analysis; Motive; Philanthropy.

JEL classification: C91, D01, D64.

\section{Introduction}

Issues related to charitable donating have been researched not only in the behavioural sciences, psychology or economics; experts in the fields of marketing, fundraising and political affairs also deal with them. Non-profit studies analyse donorship especially as regards its potential to increase the share of private resources in incomes of non-profit organisations. Therefore, many authors (Schervish, 1997; Sargeant, 1999; Bekkers, Wiepking, 2010, Gittell, Tebaldi, 2006; Marx, Carter, 2014; Andreoni, Payne, 2011; Lammam, Gabler, 2012 and

\footnotetext{
Marie Hladká; Masaryk University, Faculty of Economics and Administration, Department of Public Economics, Lipová 41a, 60200 Brno, Czech Republic, <marie@ @ladka.cz>.

Vladimír Hyánek; Masaryk University, Faculty of Economics and Administration, Department of Public Economics, Lipová 41a, 60200 Brno, Czech Republic, <hyanek@econ.muni.cz>.

The article is processed as an output of a research project The Impact of Public Financing on the Structure of Resources and Production of Non-Profit Institutions registered by the Grant Agency under the registration number GA14-06856S.
} 
Hladká, M.-Hyánek, V.: Explanation of the Donor Decision-making Process in the Czech Republic through a Combination of Influences of Individual Motives.

other) still ask the question: what are the variables that influence donors' behaviour both positively within the sense of its volume or frequency and negatively within the sense of its restriction or absence?

The current social sciences literature that identifies factors with an influence on donating is considerably extensive. Of course, its approaches and methodologies depend on a specific scientific discipline, the nature of an applied empirical investigation and also on the respective motivation agent being analysed. Most studies deal only with a specific variable. The authors (Schervish, 1997; Bekkers, Wiepking, 2010 and others) who attempt to provide a complex picture of motives that encourage individuals to make donations are not numerous. We divided the variables impacting the process of the donor's decision-making into internal and external ones. It is a division that is neglected by some researches (Lloyd 2004; Marx, Carter, 2014 and others) who interconnect individual variables, creating an unclear picture of the motives influencing the donor's decisions. However, in our opinion it is necessary to differentiate between internal variables, which arise from the underneath of individual people and create their nature and personality, and external variables, which are independent of specific individuals although they may influence them.

\subsection{Theoretical Starting Points of the Research}

The starting points for the classification of the motives having an influence on donating and subsequent empirical tests are microeconomics models that may be used to interpret donating in accordance with the microeconomics apparatus. These models work with the level of utility gained by the donor, specifically considering three basic types of benefits. Donating is based on various obvious or hidden motives and brings the individual various benefits. The following table classifies three basic types of benefits of an act of donating for the donor.

\section{Tab. 1: Potential benefits from an act of donating}

\begin{tabular}{ll}
\hline Benefit & Benefit source \\
\hline Altruistic benefit & $\begin{array}{l}\text { The benefit is based on an improved condition of a donee. The } \\
\text { donor is interested in increasing other people's benefits. }\end{array}$ \\
Personal benefit & $\begin{array}{l}\text { The donor obtains his or her own benefit from an act of } \\
\text { donating (warm-glow, social integration, etc.) }\end{array}$ \\
Exchange value benefit & $\begin{array}{l}\text { In exchange for his or her donation, the donor obtains benefits } \\
\text { such as experience, influence, information, etc. }\end{array}$
\end{tabular}

Source: Authors, adapted according to Ziemek (2003).

Economists consider the above specified sources of benefits to be the key ones in explaining the donor's behaviour. We can use the definitions of these three benefits as the basis on which we can build four microeconomics models depicting 
the process of the donor's decision-making. The given models and their basic motives are shown in the following table.

Tab. 2: Microeconomics models explaining an act of donating

\begin{tabular}{|c|c|c|}
\hline Model & Benefit & General motive \\
\hline Public Goods Model & Altruistic benefit & To increase the offer of public goods \\
\hline $\begin{array}{l}\text { Private Consumption } \\
\text { Model }\end{array}$ & Personal benefit & $\begin{array}{l}\text { To be pleased by an act of donating, the } \\
\text { "warm-glow" utility }\end{array}$ \\
\hline Investment Model & $\begin{array}{l}\text { Exchange value } \\
\text { benefit }\end{array}$ & $\begin{array}{l}\text { To gain experience, knowledge and contacts } \\
\text { on the labour market }\end{array}$ \\
\hline Impure Altruism Model & $\begin{array}{l}\text { Altruistic/personal } \\
\text { benefit }\end{array}$ & Combination of the first and the second model \\
\hline
\end{tabular}

Source: Authors, adapted according to Ziemek (2003).

\subsection{Public Goods Model}

The public goods model is based on the assumption that the individual makes donations to increase the overall offer of available public goods or services. If we accept the assumption that public goods are characterized as non-rivalrous and noexcludable in their character, the donor (as well as donee) gets a benefit (utility) through increasing benefits of other people who consume the public goods. The behaviour of the individual making a donation and increasing benefits of other people without obtaining anything in exchange can be described as altruistic. The existence of the specified positive social feelings arising from interactions between people, especially altruism, was recognized by a number of important economists, starting from Smith and Mill and ending with for example Walras or Paret. Preferences of an altruist are not defined by means of the level of their own consumption but by the level of other people's consumption (Kolm, 2000 and others). Boulding and Vickrey were among the first modern economists who rationalized donating. They were followed by Becker (1974) who created a formal model of such behaviour. ${ }^{1}$

\subsection{Private Consumption Model}

Contrary to the previous model, donors are motivated directly through an act of donating. It can be expected that people feel like making a donation because it brings them some status or praise, experience or warm-glow (Andreoni, 1989). This means that the total consumption of public goods and services has no influence on the individual's decision whether they will make a donation or not. Badelt (1985) classifies all these components entering the utility function of the individual, calling them Eigenvalues.

\footnotetext{
${ }^{1}$ Various alternatives of the given model are also presented by Schwartz (1970), Collard (1979).
} 
Hladká, M. - Hyánek, V.: Explanation of the Donor Decision-making Process in the Czech Republic through a Combination of Influences of Individual Motives.

Compared to the previous model, the model includes the assumption that donations made by others cannot be characterized as a perfect substitute for personal wealth. This implies that the individual's decision whether they will make a donation is independent on the level of contributions provided by other individuals and the individual's own contribution cannot be considered identical (substituted) with donations made by others.

\subsection{Investment Model}

Another type of a benefit arising from an act of donating is the exchange value benefit. It can be assimilated to quid pro quo or providing a service in exchange for another service. Although this benefit is typically associated with the donation of time (volunteer work), it can be theoretically related to the whole concept of donating. According to this model, donating also brings benefits in the form of our increased value on the job market through accumulating human capital, practicing and learning new skills, obtaining new contacts or the possibility to present our competency to future employees (Duncan, 1999). Because we abnegate our existing revenues in favour of future revenues, the donating that is based on value exchange can be considered to be an investment behaviour (Badelt, 1985).

\subsection{Impure Altruism Model}

The impure altruism model differs from the above specified three models in working with a mixture of various motives of donating, not just one characteristic motive. The donor's utility is given by his or her own consumption, the total offer of public goods and his or her own contributions to public goods. In this model, own contributions enter the utility function twice. Once as a part of public goods and once as private good. In accordance with what was stated, there are two types of the donor's motivation: the motivation arising from an increased offer of public goods and the motivation arising from the very fact of donating (Becker 1974, Andreoni 1989).

\subsection{Classification of Motives for the Use of Empirical Testing}

On the basis of theories formulated using the public goods model, private consumption model, investment model, and impure altruism model (Ziemek, 2003), three basic groups of motives underlying donors' decision-making have been identified. Those are altruism, egoism and investment.

For the use of our own empirical testing, we herein present our own identification and classification (based on the previous theoretical economic models) of the most important variables that we are able to come across in various researches. Because we do not know all the existing internal variables that enter the process of the donor's decision-making, we use only those that have been identified in the most significant studies. They include first of all Becker (1974), Arrow (1974), Collard (1979), Batson (1991), Andreoni (1989), Andreoni(1990), Schervish (1997), 
Sargeant (1999), Kolm (2000), Bennett (2003), Kottasz (2004), Lloyd (2004), Smith (2005), Ranganathan, Henley (2008), Bekkers, Wiepking (2010), and Marx, Carter (2014).

Outcomes of the research survey will be presented and the following motives analysed: with respect to altruism, they included empathy, affection, fellowship, compassion, solidarity, mercy, pity, respect, gratefulness, social rules, believing in justice, conviction, social responsibility, moral duty, and religious obligation. With respect to egoism, they included profit/remuneration opportunity, desire for power, self-centredness, recognition, political influence, the feeling of irreplaceability, fear, concerns, warm-glow, reciprocity, conscience, desire to sacrifice oneself, reputation, doing a good turn to society, the need to help, the need of belonging. In the case of investment, they included personal contacts, skills, socio-economic status and job opportunities.

Individual variables measuring was done partly through scaled scores. This means that one variable is expressed by means of several indicators; such approach allows us to inspect the variables from different perspectives (e.g. warm-glow I, warm-glow II).

\section{Data and Methodology}

The number of researches that have been conducted about private donations to NGOs in the Czech Republic is very limited (for example Frič, 2001; Hladká, Šinkyř́íková, 2009). We therefore executed our own empirical testing that focused on all factors that could influence donating, i.e. internal and external factors. The objective of the research was to identify factors that have an influence on decisions to donate financial means to non-profit organizations taken by individuals in the Czech Republic, and to analyse these factors as regards their mutual relationships. As it has been stated herein above, this paper however focuses on presenting the outcomes that only capture an influence of internal variables, i.e. motives. The data were collected through a questionnaire survey (all data referred to 2013).

The questionnaire was divided into three parts. In the first one, the respondent was asked whether he or she donated or not the money to non-governmental organisations in 2013 and what made him or her to do so. The second part of the questionnaire examined motives, opinions and standpoints influencing the act of donating by means of an evaluation score. Both motives and determinants were included among individual statements. Respondents could express their opinions on the scale showing the rate of identification with the respective statement. The third part of the questionnaire was focused on information about the respondent's socio-demographic profile. 
Hladká, M. - Hyánek, V.: Explanation of the Donor Decision-making Process in the Czech Republic through a Combination of Influences of Individual Motives.

Interviewer: A questionnaire survey was the primary source of data. Interviews have been conducted done by a trained team supervised and methodically supported by the authors of this paper.

Respondents: The personal interview survey was carried out in March and April 2014; a total of 442 completed questionnaires were obtained. The basic set consisted of the population over the age of eighteen, living on the territory of the Czech Republic. Furthermore, the authors worked with available (random) sampling, when people who are "at hand" are selected to comprise a set (sample) of respondents. Conclusions resulting from the analysis are therefore related only to this selective set.

The data collection phase was followed by an analysis of the collected data. The obtained data were analysed by means of mathematical-statistical methods that are commonly used in similar cases: Functions for the correlation analysis: the Pearson correlation coefficient (establishes how strong is a relationship between variables), the ANOVA method based on the F-test.

The analysis of motives was conducted in a context of the exploratory factor analysis. The indicator of the Kaiser-Meyer-Olkin (KMO) measure was applied to assess appropriateness of the factor analysis. The data suitability was tested by means of the null hypothesis that the correlation matrix of the given variables is the identity matrix. If the null hypothesis is rejected, the factor analysis makes sense. The Bartlett's test of sphericity was used to test this null hypothesis.

The factor analysis procedure can be mathematically described as a representation of the studied standardized $\mathrm{Xi}$ variables using the linear combination of the smaller number of hypothetical $\mathrm{Fj}$ factors as follows:

$$
\mathrm{Xi}=\mathrm{ai} 1 \mathrm{~F} 1+\mathrm{ai} 2 \mathrm{~F} 2+\mathrm{ai} 3 \mathrm{~F} 3+\ldots . .+\operatorname{aim} \mathrm{Fm}+\mathrm{ei},
$$

for $\mathrm{i}=1,2,3, \ldots \mathrm{k}$, where $\mathrm{k}$ is the number of manifest variables, $\mathrm{m}$ is the number of factors, and ei is the specific (unique, error, residual) part of the $\mathrm{Xi}$ variable which is assumed to have the zero correlation with all the factors.

The method of factors extraction: The Principal Component method was used to determine the number of variables. The method specifies non-correlated factors that are also organized according to their variance, with the first factor having the biggest variance and the last factor having the smallest variance. The following were used to select the number of factors:

- Kaiser criterion - the eigenvalue of the factor higher than 1

- The "Scree plot" method - decisions taken by using a chart of eigenvalues of factors

- The a priori given number - we know the number of factors in advance 
- The interpretative meaningfulness - we accept a solution that we understand and that makes sense to us.

The rotation of factors: The factor analysis carried out by the authors makes use of the Varimax orthogonal rotation that minimizes the number of variables that have high loadings on every common factor. It can be described as a method that simplifies factors. Here, the simplicity function is given by the sum of the variances of the squares of factor loadings in each column. This method tends not to create one general factor.

\section{Results and Discussion}

The authors (Hladká, Hyánek, 2015) asked themselves the following questions in their previous research: What motivates individuals in the Czech Republic to provide a donation? (significance of motives)? What is the interdependence of these motives? (strength of the relationship between the motives)? On the basis of the correlation analysis, they found that the underlying motives for making a donation were altruistic motives. The following were represented among the main themes: moral obligation, respect, conviction, faith in justice, feeling good, or social responsibility. The following can be listed among the motives that have an impact on making a donation: gratitude, social rules, religious obligation, a desire for power, profit opportunity, or reciprocity.

A high value of mutual interdependence can be identified between the following pairs of motives:

- Job opportunities - profit/remuneration opportunity (Pearson correlation coefficient .634)

- Recognition - profit/remuneration opportunity (.595)

- Job opportunities - personal contacts (.586)

- Personal contacts - profit/remuneration opportunity (.569)

- Socio-economic status - personal contacts (.554)

- Job opportunities - recognition (.541)

- Socio-economic status - recognition (.508)

- Fear, concerns - empathy (.505)

- Job opportunities - socio-economic status (.504)

- Socio-economic status - profit/remuneration opportunity (.503)

- Moral duty - social responsibility (.502)

If we summarize the outcomes declaring a high mutual relationship between the motives, we will see that the variables listed under the Investment group constitute the majority of these motives. The investment motives are also significantly 
Hladká, M. - Hyánek, V.: Explanation of the Donor Decision-making Process in the Czech Republic through a Combination of Influences of Individual Motives.

interconnected with the egoistic motives. Therefore, they are rather the motives that the respondents expressed their disagreement with.

The authors believe that the conducted analyses (In: Hladká, Hyánek, 2015) generated interesting outcomes and submitted a complex picture of the motives influencing donor behaviour in the Czech Republic. However, empirical reflection of the obtained data revealed a possible direction of the next data analysis. A considerable amount of individual motives invites to reflection whether it would be possible to explain the donor decision-making process through fewer variables, whether there are certain combinations of influences of individual motives. The analysis makes up the content of the following part of the paper.

\subsection{Empirical Reflection of the Obtained Data on the Basis of the Factor Analysis}

The data were reduced in the exploratory version of the factor analysis with the aim to uncover the hidden context. Variables related to the 37 identified motives were selected for the exploratory factor analysis. From among the many items variables those were selected that statistically "belong together" (i.e. exhibit similar variability) and from which it is possible to create a new variable (factor, component). The factor analysis was carried out in the following steps:

\subsubsection{Assessment of the data suitability for the factor analysis}

The extent to which the data obtained through empirical research are appropriate was established by means of the following:

- The anti-image matrix ${ }^{2}$ with the values of the Kaiser_Meyer_Olkin measure (herein after only KMO).

- The significance the Bartlett's test of sphericity, which should be significant at least at the level of 0.05 .

\section{Tab. 3: KMO and the Bartlett's test of sphericity}

\begin{tabular}{|c|c|c|}
\hline \multicolumn{2}{|c|}{ Kaiser-Meyer-Olkin Measure of Sampling Adequacy. } & ,896 \\
\hline Bartlett's Test of Sphericity & Approx. Chi-Square & 5112,124 \\
\hline & Df & 666 \\
\hline & Sig. & 0,000 \\
\hline
\end{tabular}

Source: Authorial computation.

The value of the KMO criterion is based on the comparison of the pair and partial correlation coefficients and acquires the value of 0.896 . This indicates that the input variables are correlated and are therefore suitable for the application of the

2 Due to the voluminosity of the data, the matrix is not documented in the paper, only the KMO measure is stated. 
factor analysis. Also the Bartlett's test, that tests whether the correlation matrix of variables is the identity matrix, confirms the appropriateness of the use of the data for the factor analysis.

\subsubsection{Extraction of Factors}

The factor analysis included the factors with the variance greater than 1 (according to the Kaiser rule). Each individual factor was extracted using the principal component method. The next analysis was therefore limited to 8 factors; the first two factors explain over $35 \%$ of the variance. If we apply the 8 factors (according to the Kaiser rule), we explain $56 \%$ of the total variability.

\subsubsection{Factor Rotations, Calculation of Factor Loadings, and the Naming of Factors}

The purpose of the rotation of factors is that the originally scattered points would get grouped around one of the extracted factors. Of the basic types of rotation there was executed the orthogonal Rotation Varimax. The factor loadings represent a correlation between a factor and the related entry. The higher the correlation, the more is the factor saturated with this entry (the correlation should be higher than 0.30). The matrix of factor loadings before and after the rotation is documented in appendix Tab. 5.

It is possible to estimate from the nature of the factor loadings that factor 1 describes selfish needs, factor 2 expressions of love, factor 3 moral needs, factor 4 expressions of understanding, factor 5 emotional needs, factor 6 integration needs, factor 7 social needs, factor 8 spiritual needs. The first factor that explains $21 \%$ of the variance, contains 10 items. The first factor that explains $14 \%$ of the variance, contains 6 entries.

\section{Tab. 4: Grouping and naming of the factors of the rotated solution of the factor analysis}

\begin{tabular}{ll}
\hline Name of the factor & Variables \\
\hline selfish needs & $\begin{array}{l}\text { profit/remuneration opportunity, desire for power, recognition, } \\
\text { political influence, the feeling of irreplaceability, reciprocity, } \\
\text { reputation, personal contacts, socio-economic status, job } \\
\text { opportunities } \\
\text { affection, fellow feeling, compassion, solidarity, respect, } \\
\text { conviction I, warm-glow I, II } \\
\text { believing in justice I, II, conviction II, social responsibility I, } \\
\text { moral duty I, II, desire to sacrifice oneself }\end{array}$ \\
expressions of love & $\begin{array}{l}\text { mercy, pity, social rules, conscience, the need to help } \\
\text { empathy, gratefulness, fear, concerns, doing a good turn to } \\
\text { society I }\end{array}$ \\
expressions of understanding & the need of belonging, skills \\
\hline integration needs &
\end{tabular}


Hladká, M.-Hyánek, V.: Explanation of the Donor Decision-making Process in the Czech Republic through a Combination of Influences of Individual Motives.

social needs

spiritual needs self-centeredness, social responsibility II

religious obligation, doing a good turn to society II

Source: Authorial computation.

The conducted analyses (Hladká, Hyánek, 2015) generated interesting outcomes and submitted a complex picture of the motives influencing donor behaviour in the Czech Republic. However, empirical reflection of the obtained data presented in this paper shows, that we can explain the donor decision-making process through fewer variables.

The motives in the first analysis were identified on the basis of four theoretical microeconomic models and subsequently analysed with respect to altruism, egoism and investment. If we carefully study the new distribution of these motives (variables) in principal component (factors) in Tab. 4, we can notice that none of the component is made up of purely altruistic, egoistic or investment motives. The authors therefore believe that for further research testing motivational behaviour (on the basis of the new eight components) it is necessary to find new suitable explanatory paradigm.

\section{Conclusion}

This paper deals with the factors influencing the act of decision-taking about making a donation. These factors are determined partly by internal reasons, motives, but also variables that are given and are more or less beyond control; they are determined by the environment in which we live, grow up, get into mutual connections with the process of giving. The content of this paper is an analysis of the motives that are classified in accordance with the findings mentioned in the analysis of economic models, this means into altruistic, egoistic and investment motives.

The motivation herein means the driving forces of a psychological nature. In the framework of the donor decision making, every individual is influenced by a complex structure of motivational dispositions, which is partially innate, but partly also obtained. Jas (2000, p. 2) states that: "charitable giving is a process of exchange, which includes both economic and social values, and which is largely driven by both selfish and altruistic motives. Approaches that do not take this double character of the exchange into account always meet with difficulties in the explanation of this phenomenon." The work is conducted in the same line of thought, dividing individual motives to egoistic and altruistic ones.

In a narrower sense, the motive is seen as a "conscious intention or objective behaviour", but in the broader sense as "the goal of a behaviour, i.e. even an unaware purpose of behaviour" (Nakonečný, 1999). Even if respondents can answer the asked questions truthfully, their behaviour does not necessarily have to 
be always in full compliance with it. In fact, their decisions about making a donation can be influenced by variables that an individual does not necessarily have to realize and that hence predetermine his or her behaviour to be hard to describe. Human behaviour is random and it can be very hard to model it. Therefore, when human behaviour is assessed, there is usually a certain space left for its unexplainable part.

A considerable amount of individual motives invited the authors to reflection whether it is be possible to explain the donor decision-making process through fewer variables, whether there are certain combinations of influences of individual motives. The data were reduced in the exploratory version of the factor analysis with the aim to uncover the hidden context. An analysis was conducted to create 8 new variables out of the original 37 variables according to logical groupings. The authors believe that these new variables create a suitable basis for the subsequent testing of the motivational behaviour of donors.

\section{References}

Andreoni, J., 1989. Giving with Impure Altruism: Applications to Charity and Ricardian Equivalence. Journal of Political Economy 6, 1447-1458.

Andreoni, J., 1990. Impure Altruism and Donations to Public Goods: A Theory of Warm-Glow Giving. The Economic Journal 401, 464-477.

Andreoni, J., Payne, A., 2011. Is crowding out due entirely to fundraising? Evidence from a panel of charities. Journal of Public Economics 5-6, 334-343.

Arrow, K., 1974. Gifts and Exchanges. Philosophy and Public Affairs 4, 343-362.

Badelt, Ch., 1985. Politische Ökonomie der Freiwilligenarbeit: theoretische Grundlegung und Anwendungen in der Sozialpolitik. Campus Verlag, New York.

Batson, C. D., Shaw, L. L., 1991. Evidence for Altruism: Toward a Pluralism of Prosocial Motives. Psychological Inquiry 2, 207-227.

Becker, G. S., 1974. A Theory of Social Interaction. Journal of Political Economy 6, 1063-1093.

Bekkers, R., Wiepking, P., 2010. A Literature Review of Empirical Studies of Philanthropy: Eight Mechanisms That Drive Charitable Giving. Nonprofit and Voluntary Sector Quarterly 5, 924-973.

Collard, D., 1979. Altruism and Economy: A Study in Non-Selfish Economics. The Economic Journal 355, 681-683.

Duncan, B., 1999. Modeling charitable contributions of time and money. Journal of Public Economics 2, 213-242.

Frič, P., 2001. Dárcovství a dobrovolnictví v České republice: (výsledky výzkumu NROS a Agnes) /Donating and Volunteering in teh Czech Republic: (Results of the Research Executed by NROS and Agnes/. 1st edition. Agnes, Prague. 
Hladká, M.-Hyánek, V.: Explanation of the Donor Decision-making Process in the Czech Republic through a Combination of Influences of Individual Motives.

Gittell, R., Tebaldi, E., 2006. Charitable Giving: Factors Influencing Giving in U.S. States. Nonprofit and Voluntary Sector Quarterly 4, 721-736.

Hladká, M., Šinkyříková, T., 2009. Dárcovství v očích veřejnosti /Donating as Seen by the General Public/. Společnost pro studium neziskového sektoru, Brno. Hladká, M., Hyánek, V., 2015. Motives for Donating: What Inspires Our Decisions to Make a Donation to Non-profit Organisations? Review of Economic Perspectives 4, 1-16. Not publish yet.

Jas, P., 2000. A gift relationship? Charitable giving in theory and practice. National Council for Voluntary Organisations, London.

Kolm, S. Ch., 2000. Introduction to the Economics of Reciprocity, Giving and Altruism. In Gérard-Varet, L., Kolm, S. Ch., Mercier Ythier, J. The economics of reciprocity, giving, and altruism. St. Martin's Press, New York.

Kottasz, R. et al., 2004. Differences in the Donor Behavior Characteristics of Young Affluent Males and Females: Empirical Evidence from Britain. Voluntas: International Journal of Voluntary and Nonprofit Organizations 2, 73-96.

Lammam, Ch., Gabler, N., 2012. Determinants of charitable giving: A review of the literature. Fraser Institute. Available from: <http://www.fraserinstitute.org/ publicationdisplay.aspx $? \mathrm{id}=18071 \&$ terms $=$ determinants+of + charitable+giving $>$.

[24 January 2014].

Lloyd, T., 2004. Why rich people give. Association of Charitable Foundations, London.

Marx, J., Carter, V., 2014. Factors Influencing U.S. Charitable Giving during the Great Recession: Implications for Nonprofit Administration. Administrative Sciences 3, 350-372.

Nakonečný, M., 1999. Sociální psychologie /Social Psychology/. 1st edition. Academia, Prague, 287.

Ranganathan, S. K., Henley, W. H., 2008. Determinants of charitable donation intentions: a structural equation model. In International Journal of Nonprofit and Voluntary Sector Marketing 1, 1-11.

Sargeant, A., 1999. Charitable Giving: Towards a Model of Donor Behaviour. Journal of Marketing Management 4, 215-238.

Schervish, P. G., 1997. Inclination, Obligation, and Association: What We Know and What We Need to Learn about Donor Motivation. Critical Issues in Fund Raising, 110-138.

Schervish, P. G. et al., 1997. Social participation and charitable giving: A multivariate analysis. Voluntas: International Journal of Voluntary and Nonprofit Organizations 3, 269-281.

Schwartz, R. A., 1970. Personal philanthropic contributions. Journal of Political Economy 6, 1264-1291. 
European Financial and Accounting Journal, 2016, vol.11, no. 1, pp. 23-38.

Smith, A., 2005. Teorie mravních citů/The Theory of Moral Sentiments/. Liberální institute, Prague.

Ziemek, S., 2003. The economics of volunteer labor supply: an application to countries of a different development level. Peter Lang, New York. 
Hladká, M.-Hyánek, V.: Explanation of the Donor Decision-making Process in the Czech Republic through a Combination of Influences of Individual Motives.

\section{Appendix}

The matrix of factor loadings before and after the rotation

\begin{tabular}{|c|c|c|c|c|}
\hline & \multirow{2}{*}{\multicolumn{2}{|c|}{$\begin{array}{l}\text { Component Matrix } \\
\text { Component }\end{array}$}} & \multirow{2}{*}{\multicolumn{2}{|c|}{$\begin{array}{c}\text { Rotated Component } \\
\text { Matrix } \\
\text { Component }\end{array}$}} \\
\hline & & & & \\
\hline & 1 & 2 & 1 & 2 \\
\hline Empathy &, 512 & &, 503 & \\
\hline Affection, fellow feeling &, 577 & & 611 & \\
\hline Compassion, solidarity &, 513 &,- 339 & ,615 & \\
\hline Mercy, pity &, 526 &,- 380 & ,649 & \\
\hline Respect & ,479 &,- 337 &, 586 & \\
\hline Gratefulness & ,389 & & & , 430 \\
\hline Social rules &, 542 & & ,311 & 497 \\
\hline Believing in justice I & ,480 &,- 501 & ,682 & \\
\hline Believing in justice II &, 546 & &, 551 & \\
\hline Conviction I & ,433 &,- 364 &, 564 & \\
\hline Conviction II & ,420 & & ,495 & \\
\hline Social responsibility I & &, 321 & & ,341 \\
\hline Social responsibility II & ,486 &,- 366 & ,608 & \\
\hline Moral duty I & ,496 &,- 460 & ,671 & \\
\hline Moral duty II & ,493 &,- 374 & 619 & \\
\hline \multicolumn{5}{|l|}{ Religious obligation } \\
\hline Profit/remuneration opportunity &, 358 & 680 & & ,762 \\
\hline Desire for power & ,329 &, 575 & & 659 \\
\hline Self-centredness & & ,424 & & ,464 \\
\hline Recognition & ,469 & ,591 & & ,754 \\
\hline Political influence & ,443 &, 363 & &, 553 \\
\hline The feeling of irreplaceability &, 525 &, 359 & &, 598 \\
\hline Fear, concerns &, 563 & &, 523 & \\
\hline Warm-glow I &, 565 &,- 491 & ,746 & \\
\hline Warm-glow II &, 596 &,- 305 & ,662 & \\
\hline Reciprocity & & 600 & & ,609 \\
\hline Conscience & ,472 & & ,399 & \\
\hline Desire to sacrifice oneself & ,399 &,- 464 &, 594 & \\
\hline Reputation & .589 & 403 & & 670 \\
\hline
\end{tabular}


European Financial and Accounting Journal, 2016, vol.11, no. 1, pp. 23-38.

\begin{tabular}{|c|c|c|c|c|}
\hline Doing a good turn to society I & ,409 & & & ,343 \\
\hline Doing a good turn to society II & ,408 & & ,345 & \\
\hline The need to help &, 366 & &, 367 & \\
\hline The need of belonging &, 536 & & ,425 &, 327 \\
\hline Personal contacts & ,413 &, 584 & & ,715 \\
\hline Skills & ,447 & & & ,445 \\
\hline Socio-economic status &, 518 &, 521 & &, 725 \\
\hline Job opportunities & ,424 & 671 & & ,792 \\
\hline
\end{tabular}

Exctraction method: Principal Component Analysis. 
